\title{
Special Aspects of Studying the Internet as a Marketing Communication Channel of the Service Industry
}

\author{
Anastasia Andreevna Sozinova \\ FSBEI HPE "Vyatka State University”, 61000, Russia, Kirov, Moskovskaya, 36 \\ Olga Vasilevna Fokina
}

FSBEI HPE "Vyatka State University", 610000, Russia, Kirov, Moskovskaya, 36

Doi:10.5901/mjss.2015.v6n4s1p139

\begin{abstract}
The main feature of modern society development is its irreversible informatization. All the areas of activity involve the processes of obtaining and processing information. In the 1990s the Internet became an essential communication marketing channel. This marketing communication tool is largely implemented by introduction of information technologies in sales and distribution of goods and services. Internet marketing as an area of a company's business activity provides ample opportunities for addressing the tasks of marketing optimizing. Offer of goods and services is made at the moment when a potential consumer refers to Internet resources, and it has a customized form. Implementation of Internet marketing, which provides a means for the creation of consumer value of goods, i.e. supply of quality goods and services in accordance with customer's needs, is based on the corporate integrated information system with access to global Web resources. The main advantage of the Internet as a tool for promoting products and services is faster implementation of an advertising campaign, convenience and direct coverage of a company's target audience.
\end{abstract}

Keywords: marketing, communication channel, Internet marketing, information system, promotion of products and services, customer value, media industry.

\section{Introduction}

Information is a key economic factor and an object of commerce in the age of economic globalization and information society. At the present stage of development, effectiveness of the creation and management of knowledge determines competitiveness both of the national economy in general and of the service industry as its integral part. An information product by virtue of its intangible nature possesses some specific properties that arise in the course of its circulation in the market.

Current state of companies in the market is characterized by increased level of competitiveness due to constantly increasing number of sellers of goods and services and launching new and updated offers, as well as reorientation of business processes on the background of the Internet technologies rapid development. All this makes business owners look for new methods and technologies for the promotion of their goods and services.

The media industry plays a crucial role in the evolution of communication channels on the Internet, based on the opportunities of cross-media systems. K. Rattan notes that publishing houses "historically acted as a mediator between creators and consumers of content. These functions persist also in the age when other forms of communication grow and evolve, going beyond the boundaries of the printed word" [Rattan, 2007]. The process of production of any type of marketing communications is still aimed at creating only one communication channel (Internet, printed media, TV, radio), instead of becoming a cross-media information flow, interconnecting all the channels of media communication.

The need for solving complex and multidimensional problems related to the transformation of the publishing industry in the context of the unstable environment determines the relevance of the issue.

The study of the term "information economy" has shown that the most unbiased statement of the problem was provided by M. Porat [Porat, 1977]. Thus, according to M. Porat, information economy is the economy of information goods and information and communication technologies where information goods are represented in digital form ("can be digitized") (Information resource on the innovations and ideas for business development).

I. Strelets points out that "network economy" is the area where online goods are produced, distributed and consumed [Strelets, 2006]. This area of relationships contributes to the GDP of the country in which a business operates. 
Development of communication technologies is the driving force behind the transformation of the society in the age of information and network economy. Development of communication channels makes it possible to provide information to large social groups, manage the motivation and behavior of the society. Therefore it is necessary to manage modern economic systems.

\section{Methodology}

In the context of hypercompetition and increasing mobility of organizations an essential prerequisite of effective functioning is professionalization, ability to work in a variety of cross-cultural, national and professional economic environments.

A. Fetisov asserts that the basic methods of functioning of a superprofessional company are knowledge management and creation of leader teams [Fetisov, 2010].

Today the Internet is the infrastructure, where the work of such superprofessionals is possible.

From year to year users more and more often refer to the Internet for information, use e-mail, read news, download software, carry out banking or financial transactions and make online purchases [Firsanov, \& Gambaryan, 2014].

Purchases in online stores are gradually becoming the usual practice. Currently Internet users have become much more interested not only in news and entertainment information, but also in materials that can help in business development.

A company's desire to maximize profits makes it searching for different ways of making its products accessible to the greatest number of customers. Unique Internet technologies, that make it possible to shop from the comfort of one's home, enable businesses to attract more potential customers.

Today, the issue of creating one's Internet presence is highly relevant. More and more companies realize the importance of creating a website. Many companies are starting to realize that the Internet is a new source of income, which returns profit 24 hours a day and attracts more and more potential customers.

According to the research carried out by the Russian online magazine "Business Online", the sales growth increases from 5 to 20\% after creation of a company's website [Firsanov, \& Gambaryan, 2014].

The Internet can provide to the user all the necessary information about a company, such as: company overview, description of goods and services, prices, contact information and even customer reviews. It makes it possible for a company to attract potential customers and get them interested.

A website is first of all an information resource for visitors.

A website provides primarily useful, necessary information about a company, its products and services, prices and discounts, as well as contact information. It can also feature colorful pictures with a description of the product, its specifications and functional characteristics.

The information provided on a company's website must meet the following criteria:

- consistency with the purposes of the website;

- taking into account the characteristics of the target audience;

- uniqueness;

- timeliness;

- objectivity and reliability.

The most important point is that a website increases a company's profit. First of all, it is due to the growing number of potential customers who come to the website via the Internet. This is because more and more people prefer to find the information they need on the Internet. People, who have access to the Internet, can save their time and purchase any product or service in the comfort of their home. According to statistics, $50 \%$ of the total number of Internet users make purchases in online stores.

By creating a website a company can get access to the audience of many thousands of Internet users, number of which increases every year. This in turn makes it possible to constantly expand the customer base.

The difference between companies that have a website, and those that don't, is that the first company has two sources of information about the product and services, and the second company has only one source of information. Accordingly, the second company has only one group of people capable to get information.

A website is not only an additional service, but also an important marketing tool making it possible to find out the interests of the target audience, to strengthen the company's image, to promote the brand, to attract potential customers and partners.

The main opportunities and benefits of promotion of a company on the Internet over other media are:

- $\quad$ targeting (accurate coverage of target audience (geographical, temporal, according to thematic websites, etc.); 
- $\quad$ tracking (capability to analyze visitors' behavior on the website and improve the website);

- $\quad$ availability (24 hours day, 7 days a week);

- flexibility (starting, adjusting and ending the search);

- $\quad$ interactivity (capability to communicate with the seller and with the product);

- capability to host large amounts of information (including graphics, sound, special effects);

- prompt dissemination and receiving of information;

- relatively low cost;

- more focused attention of a user in front of a computer, capability to understand the details [Konstantinov, 2011].

The disadvantages of the Internet as a customer acquisition tool are the following:

- the Internet is a relatively new marketing channel, and many customers are still wary of purchasing over it;

- $\quad$ with the growth of competition the number of products sold over the Internet rises; besides, many products have the same consumer characteristics, which results in the need for companies to create and use more efficient methods of sales promotion and motivation of potential customers;

- $\quad$ abundance of information on the Internet leads to users' information overload [Mamykin, 2011].

That is why the specific characteristic of working on the Internet are now transition from universality to uniqueness, willingness to execute complex activities, using integrated methods, tools and ways of thinking.

The important point is also that the Internet as a communication marketing channel has gained popularity relatively recently. But now it is the most efficient and cost-effective tool to promote products and services of a company.

The most popular service right now is creation of websites and promotion in search engines. This is due to the fact a good and easily accessible website can bring more profits to a company. Now even the smallest companies aspire to create websites.

However, it is becoming increasingly difficult to develop business on the Internet, as the popularity of this communication channel for business development has resulted in an ever-growing level of competition. Every day a plenty of new projects appear on the Web, so one has to carefully choose the right approach in order to succeed.

Also, it may be concluded that the Internet is a very efficient tool of solving marketing tasks. Exchange of information between the user and the company takes place in the shortest possible time. Currently this is a promising area of marketing development that meets all the criteria of both producers and consumers. The Russian market of goods and services successfully uses Internet resources, and communication opportunities of the global network make it possible to introduce global technologies and to promote domestic innovations.

Using the opportunities offered by the Internet introduces new features and benefits compared to the marketing based on conventional technologies.

1. Transition of the leading role from producers to consumers

In the Internet one can attract attention of a new customer within the shortest period of time, in dozens of seconds, which a user spends in front of a computer screen. However, the user can equally quickly go to any of one's competitors. In this situation, the customers' attention becomes the greatest value, and the established relationships with customers become the main capital of companies.

2. Globalization of activity and reducing transaction costs

The Internet significantly changes the spatial and temporal scale of commerce. It is a global communications medium, which has no territorial restrictions; besides, the cost of the access to information does not depend on the distance, in contrast to conventional media, where this relationship is directly proportional.

3. The time scale in the Internet environment is also significantly different from the usual time scale. High efficiency of the communication facilities provided by the Internet makes it possible to spend less time on search of partners, making decisions, making transactions, development of new products, etc. Information and services in the Internet are available 24 hours a day. In addition, its communication facilities are highly flexible, which makes it possible to easily introduce changes in the information provided, and thereby keep it up-to-date without time delay and distribution costs.

The cost of communications becomes minimal, as compared to the conventional communication media, and their functionality and scalability significantly increase.

4. Personalization of interactions. By using online interaction tools, companies can obtain detailed information on the requirements of each individual customer and automatically provide products and services that meet individual demands. One simple example is personal view of a web site for each of the customers or sending customized e-mail messages. 
The main characteristics that describe the effectiveness of online marketing as compared to conventional marketing, can be summarized as follows:

- customization of messages and special marketing offers

- focus on a particular customer and taking into account his or her individual needs;

- accurate coverage of the target audience;

- 24-hour access;

- flexibility;

- interactivity;

- relatively low cost.

To summarize, the Internet as a communication channel is needed to:

- create a favorable image of a company or its products;

- provide up-to-date information about a company, its products, prices, and many other important issues;

- make information about a company or its products available to a huge number of Internet users, including those living in remote areas;

- reduce advertising costs;

- implement all the capabilities of presenting information about the product: graphics, sound, animation, video and much more;

- get feedback from website visitors.

Thus, Internet marketing is the most effective and powerful tool for attracting customers.

The Internet environment offers an opportunity not only to provide to the customer the most complete information about products and services, but in turn to receive from customers the data needed for marketing purposes as compared to conventional media.

The main objectives of Internet marketing are:

- increasing the number of customers;

- expanding the target audience;

- increasing return on sales;

- creating a positive image and increasing popularity of the Internet resource (of the company).

There are certain tools making it possible to achieve these goals easily and effectively. The most popular tools of promotion of a company, its products and services on the Internet are:

1) Contextual advertising.

Contextual advertising is a type of Internet advertising when an advertisement is displayed in search engines (e.g. Google, Yandex) in accordance with the content and the context of a webpage (Free encyclopedia Wikipedia, The Free Encyclopedia).

Contextual advertising is selective and is displayed to the visitors of a web page whose area of interest coincides or overlaps with the area of the advertised product or service. That means that it covers the target audience directly, increasing the probability of advertising response.

It is based on the principle of keywords. Contextual advertising will be displayed to a customer who is looking for information about certain products and services by relevant keywords.

Its content is similar to the subject matter of the website. It may be hosted on any sites or in search engines (Google, Yandex).

The advantages of contextual advertising are:

- $\quad$ such advertising is targeted (Pay Per Click advertising services like Yandex.Direct and Google AdWords), they are guided by keywords and give a concrete offer to the user's request, also, when you use it, you can specify the region and the time of the demonstration);

- a large number of potential customers is covered;

- $\quad$ it is cost-effective, does not require large investments (advertisers pay not for ad impressions but for clickthroughs);

- there is a statistics function, which makes it possible to track website traffic, keywords, time of visiting and click-through rate (the ratio of clicks on the ad to the number of impressions). This, in turn, makes it possible to adjust the advertizing campaign at any time.

The main task of contextual advertising is to attract users to a company's website. The objective of a website is to convert a visitor into a customer of this company.

2) Banner advertising.

A banner is an advertisement based on a visual image. It can be a picture or a picture with accompanying text and 
a link (Wikipedia, The Free Encyclopedia).

Banners serve as a billboard on the Internet that performs three functions:

- serves as a means of brand promotion;

- informs about the company's products and services;

- serves as a tool of attracting visitors to the website of the advertised company.

Banner advertising is considered to be a popular way to attract visitors to web pages, an effective tool of attracting new customers, as well as a powerful tool of image advertising on the Internet.

3) Website promotion.

Experience has proven that the vast majority of visitors (70-90\%) come to websites with the help of search engines. Therefore, these systems play a crucial role in the process of website promotion. It is therefore very important to choose the right keywords by which the search is implemented. For this purpose, we need to optimize the website for search engine algorithms.

Website promotion is essential for getting high positions in search results, because most users view only 1 or 2 pages of search results.

Website promotion consists of several stages:

- creation of a thematic core of the website ;

- competitor analysis;

- $\quad$ optimization of the website's content (specifying keywords, elimination of errors, correction of texts);

- $\quad$ "external" (search engine) optimization (registration of the website in search engines, placement of links to the website, advertising).

It is important to remember that in order for the website to rank high in the search results, one has to make the pages of the site relevant, i.e. the content of the web site must comply with the user request.

If a company's website is optimized for search engines, this will ensure a steady customer flow.

4) Portal advertizing.

Helps to attract the audience interested in a particular topic. Portal advertizing can include: banner ads, feature articles or newsletters.

5) Email advertising.

Advantages of this type of advertising are:

- currently e-mail is used almost by all Internet users;

- email advertising reaches a specific target user;

- allows for personalized treatment;

- due to clearly defined thematic division of mailing lists one can impact directly the target audience;

- response to e-mail messages is higher than response to banner ads, and most importantly, the quality of visitors to the advertiser's website is also higher.

The main advantages of email advertising are the low cost and high speed of data exchange. A lot of businesses use e-mail to inform users about new products and services, to distribute reports and and news messages, offers for sale or purchase, etc. Email, therefore, can be used to for sending almost any text, data, graphics, sound, and video.

\section{Results}

In summary, we would like to emphasize that information communications are an essential component of any national economy, as well as of the daily life of any person. Studies of those marketing communication tools have been conducted for many years, but we can note that practical experience is significantly ahead of the development of the theoretical basis of this issue.

That is why one of the most important areas of marketing activity is the promotion of products in the market using the Internet.

The limitations of the sales market and the intensification of competition force companies to streamline the marketing activity with a view of ensuring the further successful business activity and generation of income. The most efficient solution is to improve product distribution policy on the basis of a systematic approach.

Currently the Internet as a marketing communication channel is one of the most effective marketing tools.

The Internet is known to have almost no limits in either space or time, and it is this fact that determines the explosive nature of online advertising. information placed on the Internet, provided that it is placed and focused competently, is available 24 hours a day for hundreds and thousands of people interested in this information, regardless from whether they live next door or in a remote region, in Russia or abroad. Prompt feedback in the Internet is also very 


\section{important.}

\section{Discussion}

The Internet is the technical infrastructure which makes it possible to implement a new professional revolution, that is, the emergence of a new group of professionals who work in these networks.

The specific features of the work under consideration is transition from universality to uniqueness, willingness to take cross-sectoral comprehensive actions, integration of methods, means and ways of thinking and action in the context of unstable and changing environment.

All this is due to the fact that the information product by virtue of its intangible nature has special properties, which bring in a number of effects in the course of its circulation in the market. All these features make it possible to develop a deeper and more efficient understanding of the laws of the infocommunication market. Delimitation of this market, identification of its participants and the configuration of their relationships are necessary for the planning of activities aimed at stimulation of the development and creating market infrastructure.

Information is a full-fledged part of the economic turnover in the modern society; besides it is the key resource and the major source of performance of service businesses in the new social structure - the knowledge economy. All that is related to the concept of infocommunications. This is a type of economic and marketing activity, as a result of which, on the basis of infocommunication technologies and information content, an infocommunication product is produced or a service is provided. A distinguishing feature of this process is that it doesn't produce primary content, but only transforms information received from other sectors of the national economy.

After positioning infocommunications among branches of the national economy, we believe that businesses should coordinate the activities of their divisions.

\section{Conclusion}

Taking into consideration the specificity of the services market and its distinctive features, it is necessary to explore potential new factors of economic growth of service companies. These factors should be associated with electronic communications and digital contents. An in-depth study of this problematic is impossible within the framework of this article, but we would like to point out the two processes that have good prospects - digitalization and convergence.

The first process is characterized by converting the content of marketing communications into a digital format, which reduces the time spent on search and placement of information, and results in reducing financial burden on a company and eliminating geographic boundaries of markets.

The second important process - the convergence - determines the merging of markets. Modern media industry, which is the main channel of marketing communications, is integrated with telecommunication sector, electronics and information technologies. As a result, a new market is formed consolidating multimedia services, network services and software products.

All this is due to the fact that the Internet in the modern context is the basis of creating within the shortest possible time a vast number of new information spaces available to any Internet user anywhere.

\section{References}

Bagrin, Yu. (2011). The Internet as a new marketing channel. Marketing and advertising.

Bokarev, T. (2009). Encyclopedia of Internet advertising. Moscow: PROMO-RU.

Bushueva, L. (2011). The role of Internet services in practical marketing activities. Marketing in Russia and abroad.

Golik, V. (2012). Effectiveness of online marketing in business. Moscow: Dikta.

Danko, T. (2009). Online marketing. Moscow: Infra-M.

Cozier, D. (2010). E-commerce. Moscow: Russian Editorial Board.

Konstantinov, M. (2011). Internet marketing as a tool for increasing sales. Moscow: INFRA-M.

Mamykin, A. (2011). Strategy and tactics of Internet marketing. Marketing in Russia and abroad.

Nizhegorodtseva, N. (2010). Use of the Internet in forming image communications. Saint-Petersburg: DuksNet.

Pimenov, S. (2009). Use of the Internet in the marketing system. Marketing in Russia and abroad.

Rattan K. (2007). Cross-media systems in printing and publishing industries. Choosing a strategy. Moscow: TsAPT.

Rogov, V. (2009). Online advertising as a new trend in business. Economics and life.

Rublevskaya, Yu., \& Popov, E. (2011). Modeling business in the Internet environment. Marketing in Russia and abroad.

Strelets, I. (2006). The network economy. Moscow: Eksmo. 
Uspensky, I. (2010). Internet as a marketing tool. BHV-St. Petersburg.

Fetisov, A. (2010). Management of cultures. Moscow: Delo.

Firsanov, M., \& Gambaryan, O. (2014). Russia in figures. 2012-2013. Mann, Ivanov and Ferber.

Henson, U. (2011). Internet Marketing: A practical guide. Moscow: UNITI-DANA.

Hisrik, R., \& Jackson, R. (2009). Trade and sales management. Moscow: Filin.

Kholmogorov, V. (2012). Internet marketing. Moscow: Piter.

Cherenkov, A. (2012). Internet and marketing research. Marketing and marketing research in Russia.

Wikipedia. (n.d.). The Free Encyclopedia. Retrieved March 20, 2015, from http://ru.wikipedia.org.

Information resource on innovations and ideas for business development. (n.d.). Retrieved March 20, 2015, from http://ibusiness.ru

Porat, M. (1977). The Information Economy Definition and Measurement. Wash: DC: US Dept of Commerce.

Varian, H. (1998). Markets for Information Goods. Prepared for Bank of Japan conference.

Delong, J. (n.d.). Rules, New and Old, for Tomorrow's Economy. Retrieved March 20, 2015, from http://econl61.berkeley.edu/Econ Articles/Reviews/In formation Rules.html

Sozinova, A., \& Fokina, O. (2014). Study of economic and technological factors influencing development of the services market. Life Science Journal, 11(7s), 318-321. Retrieved March 20, 2015, from http://www.lifesciencesite.com.

Sozinova, A., Fokina, O., Kalinin, P., \& Vychegzhanina, E. 2014. The Internet marketing features of main categories of ecological business: B2B and B2C. World of Scientific Discoveries, 9.1(57), 501-513. 